\title{
LECTURAS ALTERNATIVAS \\ EN LA NOVELA DEL FIN BUENO EN MAL PRINCIPIO DE DOÑA ANA FRANCISCA ABARCA DE BOLEA
}

\author{
Nieves Romero-DíAz \\ Mount Holyoke College \\ rdiaz@mtholyoke.edu
}

anto por su producción como por su consumo, la novela corta se podría
considerar uno de los géneros más señeros del Barroco español. Autores
reconocidos de la talla de Cervantes o Lope, e incluso aquellos que han gozado menos del favor de la crítica actual, verbigracia Ágreda y Vargas o Lizarazu y Berbinzana, cultivan el relato breve con acierto desigual, pero no falto de interés. Denominada, entre otros marbetes, novela cortesana (González de Amezúa 1951), novela corta romántica (Bourland 1927; Pfandl 1933), novela de cortejo (Armon 2001) o, más comúnmente, novela corta (Miñana 2002; Rodríguez Cuadros 1986; Romero-Díaz 2002; Bonilla Cerezo 2010), este conjunto de obras, bastante heterogéneas entre sí, logró un alto grado de difusión no sólo durante el siglo XVII sino también más allá del 1700, con numerosas reediciones y florilegios dentro de la península, sin desdeñar las traducciones en el exterior (Pacheco-Rasanz 1985-1986, Trujillo 2012). Pero a pesar de la aprobación del mundo editorial y lector de la época, no ha sido hasta fechas recientes, principalmente desde los años noventa del pasado siglo, cuando la novela corta ha recibido cumplida atención.

Si bien la denominación del género ha sido motivo de disputa, mayor aún se antoja el de su hechura ${ }^{1}$. En términos generales, se la podría caracterizar a partir de tres elementos argumentales (la nobleza, la corte y el amor) y dos objetivos fundamentales (el entretenimiento y la ejemplaridad) (González de Amezúa 1951). En cuanto a las influencias, habría que tener en cuenta la cuentística medieval española y los novellieri italianos (Pabst 1972). De igual manera, como se

1 Sobre la definición del género, remito al conjunto de ensayos de este volumen al igual que a la bibliografía de Bonilla Cerezo (2010). 
sabe, debe atenerse a la verosimilitud y mantenerse dentro de las variables de la misma (Miñana 2002). Sin embargo, y pese a estos rasgos generales, las novelas cortas no parecen responder a una preceptiva común, sino que se rigen por la variedad dentro de los límites precisados; así, como género proteico, se verá afectado tanto por la esclerotización de los tópicos como por la experimentación formal.

Cabe destacar la presencia de mujeres que escriben y publican novelas cortas. En efecto, si la mujer por natura es «novelera» —-según los propios autores del Seiscientos-, no parece fortuito que la mujer no solo las consuma, sino que también las produzca, introduciéndose así en el mundillo literario público (en el sentido de publicar), tan ajeno a las féminas de aquel entonces ${ }^{2}$. Se conocen cuatro novelistas en el siglo XviI español: María de Zayas y Sotomayor (Novelas amorosas y ejemplares, 1637, y Desengaños amorosos, 1647), Leonor de Meneses (El desdeñado más firme, 1655), Mariana de Carvajal y Saavedra (Navidades de Madrid, 1663) y doña Ana Francisca Abarca de Bolea (Novela del fin bueno en mal principio, inserta en su Vigilia y octavario de San Juan Bautista, 1679). Significativamente, solo la antología de «novelas cortas de escritoras» de Campbell y Whitenack (2000) incluye a Abarca de Bolea, de la cual las editoras seleccionan, junto con el mencionado relato, el Apólogo de la ventura en la desdicha. La otra antología sobre este particular hasta la fecha, en el haber de Rodríguez Cuadros y Haro Cortés (1999), ni siquiera da noticia de nuestra autora. La edición de la Vigilia por parte de Campo Guiral (1994) es la única posterior a la princeps de 1679. No es, por tanto, la Vigilia una obra demasiado conocida ni mucho menos estudiada, aunque sí menudea en los intentos de definir el género, ya sea por los estudiosos de la novela corta (King 1963), ya por los de narrativa del Siglo de Oro en general (Avalle-Arce 1975).

En las siguientes páginas, analizaré la Novela del fin bueno en mal principio, inserta en la octava jornada de la Vigilia y narrada por el anfitrión de la misma, Gerardo. La autora se refiere a esta narración interpolada como "Novela», y no "Apólogo», nombre que recibe otra de sus estructuras narrativas, respondiendo así a los elementos intrínsecos a este género: personajes nobles, espacio cortesano (o, en su defecto, urbano), temática amorosa y doble objetivo de enseñar y entretener a la vez. Entendiendo la novela como «un lugar de conflicto» en el que se negocian discursos contemporáneos a la misma (Martínez Camino 1996) y como producto cultural que interviene y actúa en la configuración social de la época en la que se inscribe (Romero-Díaz 2002), propongo estudiar la manera en que doña Ana Francisca Abarca de Bolea debate sobre los discursos de su tiempo, en particular aquellos relacionados con la mujer, examinando su posicionamiento ideológico a través de la descripción y actuación, en apariencia contradictoria, de los

La relación entre la novela corta y la mujer en su función receptora ha sido aceptada por la mayor parte de la crítica. Véase Armon (2001). 
personajes dentro del texto. Para ello, habrá que señalar las contradicciones del discurso, las tensiones resultantes, al objeto de subrayar tanto lo que la voz narrativa dice en la novela como lo que no dice, los silencios, aquellos espacios de contenido que la autora ha dejado fuera consciente e inconscientemente.

Doña Ana Francisca Abarca de Bolea, monja cisterciense del Real Monasterio de Santa María en Casbas (Huesca), es una figura bastante conocida en el ambiente social y cultural del Aragón del siglo xviI. Su familia, los Abarca de Bolea, pasa por ser una de las más ilustres de la región, con personalidades que sobresalieron en diversos campos, desde el militar al literario. Su vida en el convento se extiende a lo largo de todo el Seiscientos español, pues ingresa en 1605 con tan solo tres años y muere a finales de la década de los 80 en el mismo convento, del que solo sale en contadas ocasiones, la mayoría por razones de salud, o bien para visitar familiares y amigos en Zaragoza y Huesca (Campo Guiral 2001 y 2007). Abarca es hoy valorada por su poesía (incluida su participación en certámenes) y relaciones socio-literarias con las más prominentes figuras del ambiente aragonés, entre ellos Manuel de Salinas, Vicente Juan de Lastanosa, Juan Francisco de Uztarroz y hasta el mismo Baltasar Gracián (Campo Guiral 2000; Marín Pina 2007; Romero-Díaz 2012). Sin embargo, parece que se interesó más por su obra religiosa en prosa, de la que se siente orgullosa y sobre la que discurre con sus contertulios epistolares, solicitándoles recomendaciones ${ }^{3}$. Se trata, en fin, de cinco obras, tres publicadas en vida (Catorce vidas de las santas de la orden del Císter, 1655; Vida de Santa Susana, 1671; y Vigilia y octavario de San Juan Baptista, 1679) y dos inéditas, cuyos manuscritos se encuentran desaparecidos (la Vida de San Félix Cantalicio y la Historia de aparecimiento y milagros de la Virgen de Gloria). Como excepción, cabe destacar que, contrariamente a lo que ocurre con la mayor parte de su producción en prosa, no alude a la Vigilia ni en las cartas que se intercambia con Uztarroz o Lastanosa, ni en cualquier otra documentación relacionada con la monja previa a su publicación, la cual, además, tampoco vino de la mano directa de la autora, pues contó con la mediación de su sobrina, también monja en el convento de Casbas, doña Francisca Bernarda Abarca de Vilanova.

El silencio de Ana Francisca Abarca de Bolea alrededor de la Vigilia y su proceso editorial lleva a pensar que no tuviera intención de distribuirla — sin abandonar el dominio del manuscrito - fuera de su convento. Ya que a la altura de 1679 su defunción se antoja todavía improbable, podemos establecer algunas hipótesis a propósito de dicho silencio ${ }^{4}$. Por un lado, quizá su estado de salud, dada su edad avanzada, no le permitiera una intervención directa, delegando en su sobrina y en

3 Sobre las menciones a su obra religiosa, remito a las cartas entre Abarca y Uztarroz, incluidas en Arco y Garay (1950), y a los comentarios sobre las mismas en Guiral (2002: 241-243) y Oltra (1988).

4 Acerca de la longevidad y la muerte de Abarca de Bolea, véase Campo Guiral (2001: 249-250).

Edad de Oro, XXXIII (2014), pp. 335-349, ISSN: 0212-0429 
otros amigos y familiares la responsabilidad de dar el texto a la estampa. Por otro, no es descartable que la edición se hiciera sin su permiso, ya que, como apunta Baltasar Vicente de Alhambra, muy a pesar de la «modestia de esas señoras [tía y sobrina]», no se puede «ocultar tanto secreto» (1994: 4); o en palabras de don Tomás Abarca de Vilanova, tío de doña Francisca, «[m]ás se os debe a vos el libro, / aunque lo escribió doña Ana, / pues lo ocultó temerosa / y lo publicáis Bernarda» $(16)^{5}$. Secreto y temor podrían ser dos de las razones del silencio de doña Ana en torno a la Vigilia. ¿Sería consecuencia del carácter hasta cierto punto jovial de la obra? Tengamos en cuenta que la Vigilia se inscribe dentro del género de la miscelánea de tema pastoril a lo divino, donde la variedad se da la mano con el propósito de «enseñar deleitando». Dicha variedad nos devuelve la imagen de una escritora que domina diferentes estilos (populares y cultos) y variadas hormas (desde la poesía hasta la novela corta), pero, sobre todo, de una mujer con una capacidad intelectual que excede a la de la mayoría de damas de la segunda mitad del Seiscientos español. La miscelánea en la que aparece la obra, por tanto, es un marco ideal, puesto que, en palabras de Rallo (1984), con la miscelánea se consigue mostrar todo el saber, todas esas lecturas que a lo largo de su vida la han acompañado durante sus ratos de ocio, tan necesarios de llenar para la orden del Císter ${ }^{6}$. Abarca de Bolea, pues, llega a «elaborar lo ya investigado para dar cuenta, como en un repertorio enciclopédico, de la experiencia acumulada» (161), mostrando así un conocimiento que va más allá del de «su entorno cotidiano» (162) ${ }^{7}$. Nada mejor para evidenciar su familiaridad con la producción cultural contemporánea que la incorporación de una novela corta.

Es más que probable que Abarca de Bolea hubiera tenido acceso a las múltiples colecciones de relatos breves que se publican a lo largo del siglo xvII. De hecho, en la década de 1640, Zaragoza y, en general, Aragón, se habían convertido en el principal centro difusor de la novelística, pues como indica Pacheco-Ransanz (1985-86), «muy probablemente como resultado diferido de la prohibición propuesta por la Junta de Reformación, se produjo una ligera reorientación del mercado que favoreció sobre todo a las imprentas aragonesas, valencianas y barcelonesas» (418) ${ }^{8}$. Baste señalar que en los tórculos de Zaragoza vieron la luz las dos colecciones de Zayas (1637 y 1647) y la primera antología de novelas cortas,

5 Cito por la edición de Campo Guiral (1994), indicando la página correspondiente entre paréntesis.

6 La insistencia sobre la necesidad de ocupar el ocio se torna explícita a lo largo de toda la obra, también en los paratextos y correspondencia de sus coetáneos. De hecho, en la Orden del Cister, la ociosidad es asunto principal, incluso dentro de los Capítulos Generales. Véase Lekai (1987).

7 En la Vigilia, Abarca logra publicar sus versos (casi) completos, a manera de poemario inserto en la ficción. Como indica Marín Pina (2013), para la segunda mitad del siglo XVII decae la celebración de certámenes; de ahí la desaparición de mujeres poetas.

8 Sobre la imprenta en Aragón, véanse Cayuela (1993), Dexeus (1993), Jiménez Catalán (1927) y Velasco de la Peña (1998). 
al cuidado del famoso mercader José Alfay: Novelas amorosas de los mejores ingenios de España (1648). Aunque Pacheco-Ransanz señala la fecha de 1665 como el origen de la decadencia del género, también nos recuerda que no es correcto hablar de su desaparición absoluta, ya que las novelas se seguirían reeditando con un aumento creciente hasta bien entrado el XVIII (413-16). En este sentido, el conocimiento de la narrativa breve por parte de Abarca viene avalado por la enorme cantidad de tópicos que desliza por su Novela del fin bueno en mal principio, hasta el punto de registrarse un probable plagio del «Aviso IV» de Matías de los Reyes, perteneciente a su colección El curial del Parnaso (1624) ${ }^{9}$. Admitido o no, lo cierto es que Abarca estaba habituada a leer este tipo de libros, y que - como la de Reyes - su novela constituye un «claro ejemplo de la influencia de la precedente narrativa italiana en los escritores del siglo XVII, y es así quizá como puedan explicarse las coincidencias de estos autores» (Campo Guiral 2007: 194) ${ }^{10}$. La Novela del fin bueno en mal principio, inserta en la tarde octava de las fiestas en honor a san Juan Bautista, es narrada por Gerardo, poderoso ganadero que se aproxima más en su descripción a los contertulios nobiliarios del cuento-marco zayesco que a los pastores rústicos de las comedias de la época: galán, generoso y entendido, todo en extremo (59). La introducción de la novela se enmarca en un «palacio fingido» al que se accede por un laberinto artísticamente adornado, que hay que recorrer para llegar a su estancia principal y al jardín —una apoteosis sensorialque la rodea. Al igual que los asistentes al banquete y celebración organizados por Gerardo, el lector se adentra en una encrucijada, en este caso narrativa, pues debe reflexionar sobre discursos varios e incluso contradictorios.

Resulta significativo que el título de la novela, «Fin bueno en mal principio», se cifre en una estructura quiasmática y antitética. El quiasmo, recurso más que habitual en los estudios bíblicos, acaso frecuentados por nuestra autora, es tanto una herramienta mnemotécnica cuanto un recurso estilístico. Así, en su introducción a Chiasmus and Culture (2014), Paul y Wiseman afirman que el quiasmo representa mucho más que un «local stylistic effect» (7), explicando que el quiasmo cruzado, o sea, el del título de esta novela («fin-bueno» x «mal-principio»), responde a «our desire to see a proper and healthy order of things affirmed or restored, or it may help us to comprehend available alternatives» (26). La alteración del orden de los vocablos implica un refuerzo del orden, al tiempo que invita a pensar en alternativas. La contradicción interna creada por la antítesis hace viable, sin embargo, otra lectura que, en vez de afirmar un orden restaurado (buen fin) frente al desorden inicial (mal principio), propone una alteración y ruptura

9 Para el análisis del posible plagio, con sus paralelismos y diferencias, véanse Campo Guiral (2007: 190-194), Castillo Martínez (2007: 71-73) y King (1963: 122).

10 El baúl es, por ejemplo, protagonista en uno de los episodios de El prevenido engañado, de Zayas. 
del mismo. Como en el teatro, por tanto, es necesario tener en cuenta aquellos «discordant and conflicting elements that disagree with the harmonious conclusion intended by the code» (Regueiro 1995: 29), esto es, los elementos que han aparecido durante el desarrollo de la narración, o que se han mantenido ocultos, y que «disrupt or contradict the expected progression from order disturbed to order restored» (43). Con su virtuosismo e ingenio, Abarca introduce al receptor en un laberinto de interpretaciones, aparentemente paradójicas, que, como digo, ponen en entredicho el orden restaurado del epílogo.

La novela desarrolla la aventura de dos amigos estudiantes, portugués (Fulgencio) y milanés (Lisardo), respectivamente; galanes y nobles enamoradizos, se entregan al ocio y al cortejo durante sus años de estudio en Salamanca, pero, a causa del fracaso de sus desvelos amorosos, se aventuran por las tierras del imperio español en Europa, desde Lisboa a Milán, hasta dar con sus huesos en Madrid, felizmente casados con las damas a las que pretendieron al principio. He aquí un somero resumen del argumento, al que hay que añadir ingredientes varios que ayudan a complicarlo: engaños y desengaños, raptos y viajes, confesiones y conventos.

Dos son los únicos asedios críticos que ha merecido este relato, ambos relacionados con la posición pro o anti-misógina de la autora. Por un lado, Whitenack, tras analizar tanto la «Novela» como el «Apólogo», concluye que existe un patrón de misoginia interna, ya que la autora da rienda suelta a una crítica explícita de las mujeres engañadoras (sobre todo las del «Apólogo») y celebra a las que acatan el matrimonio. Por otro, Vollendorf inscribe la obra en el debate de la querelle de femmes, concluyendo que la excesiva negatividad de la representación de la mujer contrasta con la retórica pro-mujer del texto en su conjunto, anulándose así la citada misoginia explícita. Vollendorf llama la atención sobre tales actitudes como propias de la novelística española, ironizadas por Abarca a través de una hipérbole en grado sumo. Ambas lecturas, sin embargo, no son excluyentes, ya que ambas admiten la misoginia intrínseca al texto, aunque para Vollendorf dicha misoginia no sea sino una parodia. Con este tercer acercamiento me propongo demostrar que Abarca, sin salirse del decoro que le impone su condición de mujer noble, religiosa y escritora, por ese orden, llega a cuestionar el statu quo del patriarcado, denunciando — de forma sutil— la situación de la mujer discreta, decidida e ingeniosa, que acaba siendo víctima de dicho sistema. En la Novela del fin bueno en mal principio, la autora nos introduce en el laberinto de los discursos sociales sobre lo femenino, haciéndonos reflexionar sobre sus contradicciones, de manera que la historia resulta ser mucho más compleja de lo que a priori parecía. Así, insisto, el supuesto orden restaurado (matrimonial) del cierre, ese celebrado «fin bueno» del título, queda cuestionado, brindando al lector una serie de claves alternativas. 
Fulgencio y Lisardo distan mucho de ser los nobles galanes e ideales señores de otras novelas. Más parecidos al modo en que Zayas representa a muchos de sus aristócratas, estos jóvenes dejan bastante que desear por lo que atañe a su comportamiento. No en vano, deambulan por las principales ciudades del imperio español, sin hacer nada de provecho. Introducidos como estudiantes en la universidad de Salamanca, parecen bastante más dados la ociosidad urbana que al estudio. Son varias las ocasiones que el narrador alude críticamente a su diletantismo — «pocos [ratos] tiene quien quiere aprovechar» (307)—, reprochado por la misma Abarca y su orden religiosa. Don Fulgencio pertenece a un linaje portugués, Sylva por parte de padre, Alencastro por línea materna, «tan ilustres como ricos de bienes de fortuna» (307). Como segundón de la familia, encuentra en las letras una posible salida áulica. Pues bien, aunque su situación económica no parece incómoda (a diferencia de la de otros segundones de la novela y el teatro del Siglo de Oro), sus opciones de matrimoniar se ven entorpecidas, ya que el cortejo con el que se abre la novela no llega a buen término. Las damas marcan los ritmos de dicho casorio, a pesar de las prisas del caballero, no tanto porque deban asegurarse la dote, que también, cuanto por «aguardar a que Fulgencio saliese con la roja insignia del patrón de España» (314). Orden de veras elitista, ser caballero de Santiago era una legítima aspiración de la mayoría de los nobles de la época y, a partir del siglo XvI, por razones históricas, su consecución estaba bastante más relacionada con la pureza de la sangre que con la gloria militar. Significativo resulta, en este sentido, que una de las prioridades del matrimonio, además de la económica, esté asociada al hábito de Santiago, más aún cuando uno de los protagonistas es de origen lusitano. Además, tal requisito coincide con la muerte del hermano mayor, por lo que este segundón, más festejador que estudiante, aun cuando necesite probar la pureza de su sangre, exija enseguida su mayorazgo; sin embargo, su madre se lo niega, al tiempo que le recomienda que se aliste en la milicia, en concreto en la sede de Milán, pues «hacían tan buena unión las armas con las letras» (308). Fulgencio, en cambio, que no siente ninguna inclinación hacia las armas, decide seguir con sus actividades de ocio urbano, entretenido en fiestas y saraos, «divirtiéndose», en suma, de las actividades nobiliarias más tradicionales. El personaje de Fulgencio responde así a un modelo de linajudo que en nada coincide con el habitual, ya que ha sustituido las armas por la pluma y la música, y la conquista militar por la amorosa, rompiendo así el binomio renacentista del hombre de armas y el de letras, haciendo además durante su transformación uso ostentoso de una herencia más que fortuita. Sin embargo, será el ingenio de una mujer el que cuestione tal modus vivendi cuando lo encierra en un baúl que luego sepulta en una bóveda, dejando así en entredicho también su hombría.

De Lisardo, amigo y compañero de fatigas de Fulgencio, solo sabremos que es un caballero milanés a cuyo nombre, curiosamente, nunca le antecede el «don». 
Su nobleza se pone a prueba tras el rapto de su hermana Laura por un «señor de los más poderosos de aquella ciudad» (321). Lisardo se debate sobre cómo proceder ante tamaño deshonor. El tema de la honra nos enfrenta con una doble vía: la venganza del agraviado, que necesita limpiar su reputación y restaurar el orden amenazado (Maravall 1979), o bien — como acontecerá— el silencio y la fuga de Lisardo, para no dejar a la «vista de su descrédito» (321). De nuevo, la ausencia de algún detalle narrativo para tal comportamiento resulta elocuente. Sobre todo para cualquier lector acostumbrado a una reacción muy distinta en circunstancias similares (pensemos en las tragedias valencianas de Bermúdez o Virués y en las novelas de Zayas). La cobardía implícita en la pasividad de Lisardo lo coloca en una posición sumamente vulnerable y hasta irrisoria, por lo que no sorprende que después sea engañado con facilidad por una de las protagonistas (Isbella) y caiga semidesnudo en un albañal de «profundidad tan hedionda y como de pegajosa liga» (335). El clímax del relato, de hecho, se alcanza con los dos nobles protagonistas en posiciones pasivas y con su coraje puesto en evidencia: enterrado el uno y caído en un albañal el otro, con las espadas ceñidas al cuerpo. La nobleza de estos personajes masculinos es por tanto una nobleza definitivamente en crisis y más que degradada. Sin necesidad de verter comentarios (tácitos) que dejarían a la monja del Císter en situación comprometida, Abarca es capaz de poner patas arriba la prosapia de este par de camaradas. Y, por ello, la de sus ancestros. Este orden amenazado, casi derogado, contrasta con el final de la historia: los dos amigos, junto con el duque que había deshonrado a la hermana de Lisardo, recobran cierta dignidad, pero solo en virtud del himeneo con aquellas damas de las que se habían prendado al principio, con las que se trasladan —y no es algo gratuito- a Madrid, capital del orbe imperial. Se trata, pues, de un buen final en cuanto que el orden social se restablece y centraliza según un sistema patriarcal, legitimado a su vez por las principales autoridades de la urbe: padres y deudos, obispo y corregidor (343). Sin embargo, volviendo al quiasmo intrínseco a la novela, dicho orden puede que no sea el mejor «fin»; al menos no para todos los personajes, porque, impuesto por los hombres, y más allá del casorio, acarrea la muerte simbólica cuando no física de las damas.

Los personajes femeninos son doña Clara y doña Francisca, castellanas, virtuosas y discretas que aceptan el acuerdo nupcial con los protagonistas; Flora e Isbella, las dos jóvenes engañadoras, móvil para degradar a los caballeros en el clímax del relato; y dos personajes secundarios, doña Juana de Alencastro, madre de don Fulgencio, y doña Laura, hermana de Lisardo. Excepción hecha de Laura, quien apenas interviene, todas las mujeres desempeñan un papel clave, en tanto que son responsables de decisiones que afectan al desarrollo de la novela.

Doña Juana de Alencastro, ya viuda, aspira a un segundo matrimonio y, para ello, oculta la muerte del primogénito a su segundo hijo, don Fulgencio, cuando 
este manda furtivamente a un criado para hacerse con la herencia (308). En ningún momento la voz narradora comenta nada sobre la decisión de la dama, la cual se toma, por otra parte, sin perjuicio económico para el hijo, a quien invita a alistarse y regala liberalmente con cédulas y dineros (308), amén de hacerlo «universal heredero» (320). El único aparte que podría resultar crítico con la viuda, aquel que reza «que ya hay pocos parientes tan finos como Noemí con Rut» (308), no se refiere a ella en particular sino a sus parientes, a quienes en otras novelas, junto con los criados, se les afea sus actitudes interesadas y nada entregadas para con sus familias políticas. La conducta de la madre viuda, basada en la autoprotección social y económica, contrasta con el secretismo de don Fulgencio, quien tras conocer la noticia de la muerte de su hermano, manda a un criado a Lisboa para «saber de su madre, sin darse por entendido de la desdicha de su hermano, porque su madre no le juzgara codicioso de la herencia» (308), una actitud que evidencia justo lo contrario, es decir, la codicia y falta de compasión de don Fulgencio, bastante más preocupado por sus recreos que por sus estudios.

Flora e Isbella se definen como complementos, en principio negativos, para estafar a los nobles; opuestas, pues, a las finas y discretas doña Clara y doña Francisca (nótese el uso o la ausencia del tratamiento de «doña» en el caso de las primeras). Timadoras, cierto, pero también ingeniosas, Flora e Isbella son emblemas de la discriminación que sufría entonces la mujer. Flora, a pesar de las risas del pueblo tras su muerte, deviene ante todo en una figura trágica. La primera vez que asoma en la novela lo hace acompañando a don Fulgencio, quien la «entretiene» durante una corrida de toros (314). La voz narrativa la describe como «una mujer moza» y «de lindo garbo», casada con un hombre «de pelo entre negro y cano» (314). Se introduce así el clásico motivo del matrimonio entre el viejo y la joven. Con Flora se divierte don Fulgencio, arriesgando la promesa de matrimonio hecha en paralelo a su amada doña Clara, que acaba descubriendo sus infidelidades. Arrepentido de sus galanterías, pero rechazado por su amada, se marcha a Milán. De Flora sabremos, páginas después, que su pronta viudez la ha conducido a un segundo matrimonio con un rico letrado, a quien acompaña hasta Lisboa (321). Allí se reencuentra con don Fulgencio, que al saber de su presencia en la ciudad, «no poco se holgó» (321). El uso de la lítote en esta expresión resulta otra vez significativo. A pesar del decoro, que le impide dar respuesta a la tentación de holgar con Flora, acaba sucumbiendo a sus deseos, enfatizándose así el deseo que la lítote negaba. Tras enfermar, Flora llama a Fulgencio, quien accede a visitarla sin perder un segundo, confesándole lo mucho que la ama, al tiempo que le pide en «un largo razonamiento» que no se case jamás (334). He aquí otro tópico de la novela corta del Barroco: ante la aparición del marido, la joven convence a don Fulgencio para que se esconda en un baúl, que Flora cierra con llave y manda arrojar al río (334). En otro largo parlamento, Flora explica a su esposo que cuando se 
muera, quiere que el baúl, con todas sus joyas y vestidos, lo entierren junto a ella en la misma bóveda, para que ninguna otra mujer pueda acceder a sus bienes. Las razones del discurso de Flora contrastan con «el delirio», la falta de «razón y de discurso» y el «desatino» con que se juzga su última voluntad: los hombres de la ciudad, religiosos y laicos, la describen como «mujer demente» y «loca mujer», mientras se ríen de su decisión. Las ideas de Flora, no obstante, la han situado en una posición dominante, puesto que amenaza un orden social que, por el contrario, se afana en desautorizarla. De esta manera, su acto de ingenio acaba transformado en uno de locura ${ }^{11}$. La risa de los lugareños pone freno a esa amenaza de una mujer que se había burlado del patriarcado; solo así los hombres, a modo de catarsis, se elevan sobre ella, devaluándola y, en consecuencia, restableciendo el orden tras el que se parapetan ${ }^{12}$.

En clave ingeniosa puede leerse también la historia de Isbella. La joven construye toda una ficción sobre sí misma, en la cual se hace pasar por la hermana raptada de Lisardo (doña Laura), con la intención de desposeerlo de las riquezas que este se había traído de Milán. La fingida Laura aparece ante Lisardo en un «encantado castillo» al que se accede por un «enredoso laberinto», nos dice el narrador (332). Igual que el laberinto construido por Gerardo, Isbella elabora su propio laberinto discursivo, con el que engaña al crédulo Lisardo. Luego la creatividad femenina iguala a la de los hombres, e incluso, como diría Zayas, la supera, tal y «como se ve en las respuestas de repente y en los engaños de pensado, que todo lo que se hace con maña, aunque no sea virtud, es ingenio» (2000: 22). Abarca de Bolea, como autora de la novela y de la Vigilia, finalmente se coloca al nivel de las otras novelistas de aquella centuria, haciendo gala de su agudeza y capacidad intelectual.

Isbella, transformada en Laura, embauca a Lisardo mediante una doble ficción: primero como su hermana, luego como hermana de un canónigo que aspira a un buen matrimonio. La farsa se derrumba cuando, a la llamada de la joven para presentarle al cura, Lisardo cae en un albañal repugnante, semidesnudo y «arrimado a su espada» (336). El narrador explica que, a pesar de la situación, socialmente infame, y de las ganas de vengar semejante agravio, Lisardo, «aconsejándose con su cordura y fiando en Dios», decide alejarse de la ciudad en secreto para limpiarse. De nuevo Lisardo frustra toda expectativas nobiliaria y se podría hasta pensar que la autora está subvirtiendo el código del honor, oponiéndolo a la

1 Esta relación entre ingenio y locura, discutida por Huarte de San Juan en su Examen del ingenio (1575) y tan categórica en la figura de don Quijote, se desarrolla, en relación con la mujer, en Hernández-Vogt (2013).

12 Hobbes afirma en su Leviatán (1650) que reírse mucho de los defectos ajenos es signo de «pusilanimidad», porque, de esa manera, el que ríe se siente superior. Su teoría sobre la risa se inscribe a su vez dentro de la «teoría de la superioridad», según la define Villegas Uribe (2011). 
razón y el espíritu religioso. No obstante, gracias a la fortuna, Lisardo y su amigo Fulgencio llegarán a la casa de Isbella y se decidirán a entrar, para vengarse; se comportan, como se verá, en contra de toda razón: los dos se adueñan del hogar de la muchacha «con la furia de embravecidos leones... desenvainados los aceros, amenazándola de muerte» (340). La voz narrativa incluye entonces el único comentario negativo, o de juicio moral, sobre una mujer; se refiere a Isbella como «aquella mujer o animada arpía» (340). La escena resulta un punto más que ambigua. Por un lado, el comentario avanza en paralelo a la intervención de los caballeros, quienes, fuera de sí, irrumpen embravecidos y dispuestos a no dejar títere con cabeza. Son los mismos, eso sí, que rechazaron enrolarse en el ejército o defender el honor familiar. La hombría desafiada en la novela, rebajada por mor del símbolo de las espadas envainadas, se debe reimponer socialmente, aunque sea por la fuerza. Por otro lado, la hipérbole de la descripción de la embestida contrapesa el arrepentimiento sublime de Isbella, quien, mártir en vida, se convierte, pide confesión y, entre lágrimas, hace testamento y muere, protegida por Santo Tomás de Aquino, santo «a quien creía deber el alto conocimiento que Dios le había dado» y al que siempre rezaba (341-42). La arpía Isbella se transforma, así, en la santa Isbella, modelo y ejemplo de virtud, similar al de muchas de las que Abarca de Bolea había celebrado en sus hagiografías. Significativamente, Flora e Isbella son enterradas juntas, la loca y la arrepentida, mártires ambas de un sistema patriarcal que rechaza y niega el ingenio femenino.

Doña Clara y doña Francisca son igualmente trágicas. Las primas acaban casadas con los protagonistas y, junto con doña Laura y el duque, se trasladan a Madrid, donde, según el narrador, vivieron ejemplarmente durante muchos años. $\mathrm{El}$ «buen fin» de la novela presupone una boda y una sucesión que acredite a los nobles aventureros de la trama (346). Sin embargo, las damas no parecen compartir este «buen fin»y, de modo antitético, el de los hombres (con su objetivo cumplido) no se corresponde con el suyo. Nótese cómo el silencio de las damas al final de la novela contrasta con la actividad y facundia del comienzo, cuando ellas marcaban las pautas de su idilio con los aristócratas. Las jóvenes silenciadas del epílogo, pues, nada o poco tienen que ver con aquellas «hermosas, recatadas, cuerdas y entendidas» (307). Recuérdese que doña Francisca, viuda y anciana, rechazaba cualquier oferta de matrimonio, más aún si venía de ultramar (o sea, Lisardo) (313), pero no vacila en poner fecha al de su prima con Fulgencio. Por otro lado, a resultas de la infidelidad del caballero con Flora, las damas son también las que rompen su compromiso. Para ello, antes traban amistad con Flora y su suegra, con la intención de descubrir por sí mismas aquella traición, evitando, a la postre, todo enfrentamiento (dialéctico o físico). Aunque la ruptura del acuerdo entre Clara y Fulgencio se acompaña de las tópicas lágrimas y congojas, de la palidez, flaqueza y pesar de la muchacha, esta, que se resiste a 
morir callando su desengaño, se determina a contarle la causa de sus desdichas y a ingresar en un convento (316). Incluso desde la posición de desengañada, Clara toma una decisión propia y actúa según sus designios. Las damas no volverán a aparecer hasta el cierre, cuando se desposan con su par de galanes, avalados ahora por las autoridades civiles y los deudos de ambas. Así, Francisca acaba uniéndose con Lisardo, y Clara, ya muy devota del convento de San Bernardo, con el atribulado Fulgencio (343). Eso sí, sin que en ningún momento se repare siquiera en la voluntad de dichas mujeres, ni tengamos noticia de sus sentimientos. Consumado el casorio, podría afirmarse que mueren de forma simbólica, relativizando lo suyo el «fin bueno» del título; hacen mutis, al menos, con una sonrisa en los labios, pues saben que el orden — solo en parte— restaurado también queda en tela de juicio.

Recibido: 17/09/2014

Aceptado: 30/10/2014

\section{OBRAS CITADAS}

Abarca de Bolea, Ana Francisca (1994). Vigilia y octavario de San Juan Baptista. María Ángeles Campo Guiral (ed.). Huesca: Instituto de Estudios Altoaragoneses.

ARCO Y GARAY, Ricardo del (1950). La erudición española en el siglo XVII y el cronista de Aragón Andrés de Uztarroz. Madrid: CSIC: Instituto Jerónimo Zurita.

Armon, Shifra (2001). Picking Wedlock: Women and the Courtship Novel in Early Modern Spain. Lanham, MD: Rowman and Littlefield.

(2001). «Women and the novela de cortejo». En Gwyn Campbell y Judith Whitenack (eds.), Zayas and her Sisters: Essays on "novelas" of the Seventeenth-century Women Writers. Binghamtom: Global Publications, pp.141-57.

Avalle Arce, Juan Bautista (1975). La novela pastoril española. Madrid: Istmo.

Bejarano Pellicer, Clara (2012). «Santas medievales a los ojos barrocos». Tiempos Modernos, 25, pp.1-36.

Bonilla Cerezo, Rafael (ed.) (2010). Novelas cortas del siglo XVII. Madrid: Cátedra.

Bourland, Caroline (1927).The Short Story in Spain in the 17th Century. Northampton, MA: Smith College.

CAmpBell, Gwyn y Judith Whitenack (eds.) (2001). Zayas and her Sisters: Essays on «novelas» of the Seventeenth-century Women Writers. Binghamtom: Global Publications. (eds.) (2000). Zayas and her Sisters: An Anthology of "novelas" by 17th-century Spanish Women. Asheville, NC: Pegasus.

CAmpo Guiral, María Angeles (2007). Devoción y fiesta en la pluma barroca de Ana Francisca Abarca de Bolea: estudio de la vigilia y octavario de San Juan Bautista. Huesca: Instituto de Estudios Altoaragoneses.

(2001). «Presencia de doña Ana Abarca de Bolea en el ambiente intelectual aragonés del siglo XVII». En Gwyn Campbell y Judith Whitenack (eds.), Zayas and her Sisters: 
Essays on «novelas» of the Seventeenth-century Women Writers. Binghamtom: Global Publications, pp. 235-252.

Campo Guiral, María Angeles (2000). «Ana Francisca Abarca de Bolea y el círculo lastanosino». En La cultura del barroco. Los jardines: arquitectura, simbolismo y literatura. Actas del Iy II Curso en torno a Lastanosa. Huesca: Instituto de Estudios Altoaragoneses, pp. 29-42.

Castillo Martínez, Cristina (2007). «Los relatos insertos en la Vigilia y Octavario de San Juan Bautista de doña Ana Francisca de Abarca Bolea». En Beatriz Mariscal y María Teresa Miaja de la Peña (coord.), Actas del XV Congreso de la Asociación Internacional de Hispanistas "Las dos orillas», Monterrey, México del 19 al 24 de Julio de 2004, vol. 2. México: Fondo de Cultura Económica, pp. 63-76.

Carvajal y SaAvedra, Mariana (1993). Navidades de Madrid y noches entretenidas, en ocho novelas. Catherine Soriano (ed.), Madrid: Clásicos Madrileños / Comunidad de Madrid.

Cayuela, Anne (1993). «La prosa de ficción entre 1625 y 1634. Balance de diez años sin licencias para imprimir novelas en los reinos de Castilla». Mélanges de la Casa de Velázquez, 29, pp. 51-76.

Dexeus, Mercedes (1993). «Las imprentas de la Corona de Aragón en la difusión de la literatura del Siglo de Oro». Edad de Oro, 12, pp. 71-89.

GonZÁLEZ de AmEzúA, Agustín (1951). «Formación y elementos de la novela cortesana». En Opúsculos histórico-literarios, vol. 1. Madrid: CSIC, pp. 194-279.

Hernández-Vogt, Persephone (2013). Locas atrevidas en la literatura del Siglo de Oro [Undergraduate Honors Thesis]. Department of Romance Languages \& Cultures. Mount Holyoke College, 2013.

Huarte de SAn JuAn, Juan (1989). Examen de ingenios. Guillermo Serés (ed.). Madrid: Cátedra.

Jiménez Catalán, Manuel (1927). Ensayo de una tipografia zaragozana del siglo XVII. Zaragoza: La Académica.

KInG, Willard (1963). Prosa novelística y academias literarias en el siglo XVII. Madrid: Silverio Aguirre Torre.

LeKaI, L.J. (1987). Los Cistercienses. Ideales y realidad. Tarragona: Abadia de Poblet Imp. Maravall, José Antonio (1984). Poder, honor y élites en el siglo XVII. Madrid: Siglo XXI. MARÍn PINA, María Carmen (2013). «Los certámenes poéticos aragoneses del siglo XVII como espacio literario de sociabilidad femenina». Bulletin Hispanique, 115-1, pp. 145-164. (2007). «Juan Francisco Andrés de Uztarroz y el Parnaso femenino en Aragón». Bulletin Hispanique, 109-2, pp. 589-614.

MARTínez CAMINo, Gonzalo (1996). «La novela corta del Barroco español y la formación de una subjetividad señorial». Bulletin of Hispanic Studies (Glasgow), 73, pp. 33-47.

Meneses, Leonor de (1994). El desdeñado más firme. Primera parte. Judith A. Whitenack y Gwyn E. Campbell (eds.). Potomac, Md: Scripta Humanistica.

MiÑAna, Rogelio (2002). La verosimilitud en el Siglo de Oro: Cervantes y la novela corta. Newark, Delaware: Juan de la Cuesta.

OLtrA, José Miguel (1988), «La hagiografía como pretexto autobiográfico en Ana Francisca Abarca de Bolea». En Jean Pierre Etienvre y Leonardo Romero (coords.), La 
recepción del texto literario. Zaragoza: Universidad de Zaragoza - Casa de Velázquez, pp. 77-104.

PABST, Walter (1972). La novela corta en la teoría y en la creación literaria. Rafael de la Vega (trad). Madrid: Gredos.

Pacheco-Rasanz, Arsenio (1985-1986). «Varia fortuna de la novela corta en el siglo XVII». Revista Canadiense de Estudios Hispánicos, 10, pp. 407-421.

PfandL, Ludwig (1933). «La novela corta». En Historia de la literatura nacional española de la Edad de Oro. Barcelona: Sucesores de J. Gili, pp.330-405.

RaLlo, Asunción (1984). «Las misceláneas del Siglo de Oro: conformación y desarrollo de un género renacentista». Edad de Oro, 3, pp. 159-180.

Regueiro, José M. (1995). «Textual Discontinuities and the Problems of Closure in the Spanish Drama of the Golden Age». En Marina Brownlee y Hans Gumbrecht (eds.), Cultural Authority in Golden Age Spain. Baltimore: Johns Hopkins UP, pp. 28-50.

Rodríguez CuAdros, Evangelina. «Introducción biográfica y crítica». En Novelas amorosas de diversos ingenios del siglo de XVII. Madrid: Castalia, pp. 9-81.

— y Marta Haro Cortés (eds.) (1999). Novela de mujeres en el Barroco: Entre la rueca y la pluma. Madrid: Biblioteca Nueva.

RoMERo-DíAz, Nieves (2012). «Aproximaciones a la poesía secular escrita por mujeres, 1650-1700». Caliope: Journal of the Society for Renaissance and Baroque Hispanic Society, 18-1, pp. 102-126.

(2002). Nueva nobleza, nueva novela: reescribiendo la cultura urbana del barroco. Newark (Delaware): Juan de la Cuesta.

TRujILLo, José Ramón (2012). «Apuntes para una colección de narrativa barroca». En Rafael Bonilla Cerezo, José Ramón Trujillo y Begoña Rodríguez (coords.), Novela corta y teatro en el Barroco español (1613-1685): Studia in Honorem Prof. Anthony Close. Madrid: Sial Ediciones, pp. 185-211.

Velasco de la Peña, Esperanza (1998). Impresores y libreros de Zaragoza, 1600-1650. Zaragoza: Institución Fernando el Católico.

Villegas Uribe, Carlos Alberto (2011). Psicogenésis de la risa: la risa como construcción de cultura [tesis doctoral]. Madrid: Universidad Complutense de Madrid.

Vollendorf, Lisa (2005). The Lives of Women: A New History of Inquisitional Spain. Nashville, TN: Vanderbilt University Press.

Wiseman, Boris y Anthony Paul (2014). «Introduction». En Chiasmus and Culture. Oxford: Berghahn Books, pp.1-17.

WhitenAcK, Judith (2001). «Internalized Misoginy? A Study of Two Tales of Ana Abarca de Bolea». En Gwyn Campbell y Judith Whitenack (eds.), Zayas and her Sisters: Essays on «novelas» of the Seventeenth-century Women Writers. Binghamtom: Global Publications, pp. 253-270.

ZAYAS y SOTOMAYOR, María de (2000). Novelas amorosas y ejemplares. Julián Olivares (ed.). Madrid: Cátedra.

(1983). Desengaños amorosos. Alicia Yllera (ed.). Madrid: Cátedra. 


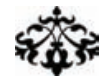 \\ LECTURAS ALTERNATIVAS EN LA NOVELA DEL FIN BUENO EN MAL PRINCIPIO de doña Ana Francisca Abarca de Bolea}

RESUMEN: En su Novela del fin bueno en mal principio, Abarca de Bolea alcanza a cuestionar el sistema patriarcal en el que está inmersa, vertiendo una crítica sutil de la situación de la mujer, la cual, a pesar de su dinamismo, ingenio y creatividad, acaba siendo víctima de dicho sistema. La novela en cuestión nos introduce en un laberinto de discursos sociales sobre la mujer de aquella época, haciéndonos reflexionar, al final, sobre el aparente orden matrimonial; más aún, sobre ese celebrado «fin bueno» del título, que invita a pensar en lecturas alternativas.

Palabras Claves: Novela corta, Laberinto narrativo, Crítica social, Personajes femeninos, Ingenio, Creatividad.

\section{Alternative Readings to the Novela del fin BUENO EN MAL PRINCIPIO by DoÑa ANa Francisca AbarCA DE BolEa}

AвSTRACT: In her Novela del fin bueno en mal principio, Abarca de Bolea manages to question the patriarchal system to which she belongs, and to subtly criticize the situation of women, who, despite their agency, ingenuity and creativity, end up falling victim to said system. The novel introduces us into a labyrinth of social discourses about women of the time and makes us reflect upon the apparent matrimonial order of the ending, that celebrated "good ending» of the title, inviting us to think of alternative readings.

Keywords: Short novel, Narrative labyrinth, Social Criticism, Female characters, Ingenuity, Creativity. 
Evangelina Rodríguez Cuadros (Universitat de València)

Novela cortesana, novela barroca, novela corta: de la incertidumbre al canon .9

Mita Valvassori (Universidad de Los Lagos)

El modelo narrativo del Decamerón en la Edad de Oro: una vieja historia .21

Antonio Gargano (Università degli Studi di Napoli Federico II)

«Difficile est proprie communia dicere»: el género de la novella entre

Boccaccio y Cervantes

Guillermo Carrascón (Università degli Studi di Torino)

Apuntes para un estudio de la presencia de Bandello en la

novela corta del siglo XVII

Leonardo Coppola (Università degli Studi «G. d'Annunzio» di Chieti-Pescara)

La proyección de Straparola en la novela española del Siglo de Oro desde una perspectiva editorial

Mireia Aldomì García

Didactismo, género literario y lector en Giraldi Cinzio.

María Jesús Zamora (Universidad Autónoma de Madrid)

«...En tiempo menos discreto que el de agora, aunque de hombres más sabios, se

Ilamaban a las novelas cuentos». La novela corta y el cuento en el Siglo de Oro.....109

Marcial Rubio (Università degli Studi «G. d'Annunzio» di Chieti-Pescara)

La contribución de Cervantes a la novela barroca: la ejemplaridad. .125

PIERRe Darnis (Université Bordeaux Montaigne)

La fuerza de la sangre, La ilustre fregona $y$ Las dos doncellas: ¿tres tipos

folclóricos?

María Soledad ArRedondo (Universidad Complutense de Madrid)

De La gitanilla $a$ La sabia Flora malsabidilla. El género, el personaje

y el matrimonio

Antonella Gallo (Università degli Studi di Verona)

Fabulaciones en equívocos burlescos: la Chrónica del monstro imaginado (1615)

de Alonso de Ledesma y novela corta barroca

David GonZález Ramírez (Universidad de Málaga)

El filósofo del aldea (1625) de Baltasar Mateo Velázquez: recepción textual

e hipótesis autorial.

Jonathan BRAdBury (University of Exeter)

La narrativa breve en la miscelánea del siglo XVII 
Cristina Castillo Martínez (Universidad de Jaén)

«La fuente del desengaño»: de las Noches de invierno de Eslava a la Tercera

Diana de Tejeda.

María Zerari (Université Paris-Sorbonne, CLEA)

Furor in fabula: La cruel aragonesa de Castillo Solórzano (o de la dama monstruo).. 241

Giulia Giorgi (Università degli Studi di Ferrara)

Alonso de Castillo Solórzano reescritor de sí mismo: algunas notas sobre los

Escarmientos de amor moralizados y el Lisardo enamorado .257

Angela Fabris (Alpen-Adria-Universität Klagenfurt)

El diálogo con el público y los espacios reales y de maravilla en

Casos prodigiosos y cueva encantada de Juan de Piña .267

María Rocío LePe García (IES San Sebastián, Huelva)

La traducción inglesa de Hipólito y Aminta: una adaptación

con fines comerciales 281

Andrea Bresadola (Università degli Studi di Udine)

La novela española en la Italia del siglo XVII: el caso de Il Feniso

de Francisco de Quintana

José Teruel (Universidad Autónoma de Madrid)

El triunfo del Desengaño. Marco y desengaño postrero de la Parte segunda

del Sarao y entretenimiento honesto, de María de Zayas

Nieves Romero-Díaz (Mount Holyoke College)

Lecturas alternativas en la Novela del fin bueno en mal principio

de doña Ana Francisca Abarca de Bolea.

Shifra Armon (University of Florida)

Compromiso y distanciamiento en La Venus de Ferrara

de Mariana de Carvajal Saavedra

Mechthild Albert (Rheinische Friedrich-Wilhelms-Universität Bonn)

Las "noches": un subgénero novelístico en perspectiva comparada.... .365

Fernando Copello Jouanchin (Université du Maine, Le Mans)

El mueble en la novela corta del Siglo de Oro: algunas reflexiones

en torno a la cama

Ilaria Resta (Università del Salento):

De la novella al entremés pasando por la novela corta: reescrituras del cuento

La gara delle tre mogli del Cieco di Ferrara. 


\section{EDAD DE ORO}

Revista de Filología Hispánica XXXIII

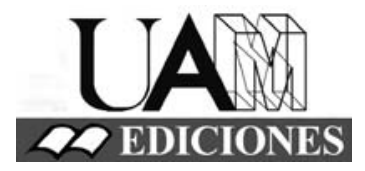




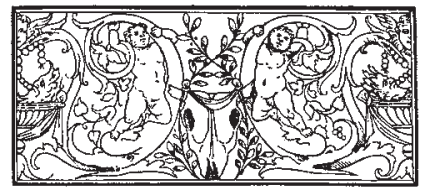

\section{Edad de Oro. Revista de Filología Hispánica}

ISSN: 0212-0429

Dirección:

Teodosio Fernández

Secretaría y edición:

José Ramón Trujillo

Coordinador del volumen XXXIII:

Rafael Bonilla Cerezo

Comité científico internacional:

Carlos Alvar (Univ. de Ginebra)

Ignacio Arellano (Univ. de Navarra)

Javier Blasco (Univ. de Valladolid)

Alberto Blecua (UAB)

Jean Canavaggio (Univ. de París X)

Laura Dolfi (Univ. de Turín)

Aurora Egido (Univ. de Zaragoza)

Víctor García de la Concha (RAE)

Luciano García Lorenzo (CSIC)

Joaquín González Cuenca (Univ. de Castilla-

La Mancha)

Agustín de La Granja (Univ. de Granada)

Begoña López Bueno (Univ. de Sevilla)

Michel Moner (Univ. de Toulouse III)

Joan Oleza (Univ. de Valencia)

Alfonso Rey (Univ. de Santiago)

Lina Rodríguez Cacho (Univ. de Salamanca)

Leonardo Romero Tobar (Univ. de Zaragoza)

Aldo Ruffinatto (Univ. de Turín)

Lía Schwartz (City University of New York)
Redacción y admisión de originales:

Teodosio Fernández

Edad de Oro

Departamento de Filología Española

Universidad Autónoma de Madrid

28049 Madrid (España)

Tfno.: +0034 914974090

correo: teodosio.fernandez@uam.es

Distribución, suscripción y venta:

Servicio de Publicaciones de la UAM

Universidad Autónoma de Madrid

28049 Madrid (España)

Intercambio de publicaciones:

Biblioteca de la Facultad de Filosofía y

Letras (UAM)

Universidad Autónoma de Madrid

28049 Madrid (España)

Han colaborado en este volumen:

Departamento de Filología Española (UAM)

Facultad de Filosofía y Letras (UAM)

Proyecto I+D FFI2013-41264-P La novela

corta del siglo XVII: estudio y edición (y II)

Edad de Oro se recoge en las siguientes bases de datos: SCOPUS, MLA Database, HLAS, Latindex, PIO-Periodical Content Index, ISOC, Dialnet, MIAR, ERIH, DICE, Sumaris CBUC, Ulrich's. Se encuentra evaluada en CIRC: A; INRECH: primer cuartil, posición 6 de 50; MIAR difusión ICDS live: 9.977; SCImago Journal \& Country Rank: H Index 2, SJR 0,101, Q4; RESH índice de impacto: 0.162; ERIH: A INT1; Carhus Plus+: B. 